\title{
La caza en Centurión. Aproximaciones etnográficas entre cazadores y conservacionistas
}

\author{
HUNTING IN CENTURION. ETHNOGRAPHIC APPROACHES BETWEEN HUNTERS \\ AND CONSERVATIONISTS
}

\section{A CAÇA EM CENTURION. ABORDAGENS ETNOGRÁFICAS ENTRE CAÇDORES E CONSERVACIONISTAS}

\author{
Magdalena Chouhy* \\ Juan Martín Dabezies**1 \\ magdalenachouhy@gmail.com
}

Recibido: 31/3/2020 Aceptado: 08/6/2020

\section{Resumen}

En este trabajo exploramos aspectos éticos, epistémicos y materiales implicados en los discursos y prácticas de caza en Paso Centurión, una localidad rural del noreste del Uruguay. Los cambios en el uso del suelo a impulsos del agronegocio, las nuevas sensibilidades globales respecto a los derechos de los animales, y los procesos de ambientalización generados en la zona, entretejen una serie de complejas relaciones con las prácticas locales de caza de subsistencia. En esta encrucijada, disímiles moralidades, conocimientos, formas de relación y gestión de los animales se confrontan y se articulan mediante puentes pragmáticos que permiten la coexistencia de una multiplicidad de relaciones humano-animal.

Palabras clave: Etnografía; Paso Centurión; Caza de subsistencia; Conservacionismo; Onto-epistemologías

\section{Abstract}

In this work we ethnographically explore the ethical, epistemic, and material aspects involved in the discourses and hunting practices in Paso Centurión, a rural town in northeastern Uruguay. Changes in land use driven by agribusiness, new global sensitivities regarding animal rights, and "green demands" generated in the area, weave a series of complex relationships with local subsistence hunting practices. At this crossroads, dissimilar moralities, knowledges, relationships and different kind of human-animal interactions coexist.

Keywords: Ethnography; Paso Centurion; Hunting subsistence; Conservationism; Onto-epistemologies

\section{Resumo}

Neste trabalho exploramos os aspectos éticos, epistêmicos e materiais dos discursos e práticas de caça em Paso Centurión, uma cidade rural no nordeste do Uruguai. Mudanças no uso da terra dirigidas pelo agronegócio, novas sensibilidades globais em relação aos direitos dos animais e processos de ecologização gerados na área, tecem uma série de relações complexas com as práticas locais de caça de subsistência. Nessa encruzilhada, moralidades, conhecimentos, formas de relacionamento e diferentes manejos dos animais são confrontados ou articulados por meio de pontes pragmáticas que permitem uma

\footnotetext{
$1 *$ Investigadora Independiente

** Centro Universitario de la Región Este Universidad de la República
} 
multiplicidade de interações humano-animal.

Palavras chave: Etnografia; Paso Centurión; Caça de subsistência; Conservacionismo; Onto-epistemologias

\section{Introducción}

Gran parte de la arqueología y la antropología del siglo XX se han dedicado al estudio de la caza desde muchos puntos de vista, pues se trata de un campo amplio y complejo. En la arqueología y de la antropología ambiental de comienzos y mediados del siglo XX, el estudio de la caza estaba muy vinculado a los grupos de cazadores-recolectores en sociedades indígenas (Binford, 1980; Harris, 1968; Lee \& Devore, 1968). En sociedades no indígenas la caza es un tema más reciente y menos desarrollado. Sin embargo, en el marco de los estudios humanoanimales, este se encuentra en franco crecimiento (Dabezies, 2017; Fernandes-Ferreira, 2014; Marvin, 2003, 2006; Montero Cruzada, 2017, 2019). En estos enfoques la caza es abordada como una forma de relacionamiento con los animales, en donde éstos no son reducidos a fuentes de proteína (DeMello, 2012; Marvin \& McHugh, 2014; Ritvo, 2007). Asimismo, la representatividad social, la ritualidad, el origen y el componente existencial de la caza son centro del interés de los trabajos sociológicos y antropológicos sobre el tema (Bozon, 1982; Chamboredon, 1982; Fabre-Vassas, 1982; Pelosse \& Vourc'h, 1982; Sánchez Garrido, 2009).

Existen diferentes modalidades para clasificar la caza. Según el tamaño de las presas, se habla de caza mayor y menor; según el objetivo de la cacería, podemos hablar de caza deportiva o caza de subsistencia. También existen variantes que priorizan la obtención de trofeos o la aventura de la cacería. En este artículo, nos centraremos en la caza de subsistencia, la cual puede ser definida como una práctica cinegética cuyo objetivo principal es el consumo de la carne o derivados. Está relacionada con la seguridad y la soberanía alimentaria en diversas regiones donde es importante incluso como fuente de alimento principal (Carpinetti y Fa, 2012; De la Montaña Andrés, 2013; Cordeiro Rosas y Drumond, 2007; Kumpel, Milner-Gulland, Cowlishaw y Rowcliffe, 2010; Lowassa, Tadie y Fischer, 2012).

En Uruguay la caza abastece de carne diariamente a familias rurales, pueblos y ciudades del interior (MNHN, 2017) . Pero la caza de subsistencia no está contemplada por la normativa uruguaya de regulación de la actividad cinegética. El decreto que regula la caza en Uruguay establece diferentes categorías de caza, pero en ningún caso se menciona la caza de subsistencia, lo que genera una serie de situaciones legales grises, donde chocan los derechos a la alimentación y la soberanía alimentaria con las restricciones relativas a la gestión de la fauna nativa. Asimismo, aspectos culturales, epistemológicos y ontológicos entran en contradicción con la política racional de fauna.

El presente artículo indaga en la caza de subsistencia a partir de un estudio de caso etnográfico desarrollado entre el 2015 y 2018 en Paso Centurión, una localidad rural del noreste del Uruguay. Más que un medio de subsistencia, la caza ha sido históricamente parte del modo de vida y una forma de relacionamiento de las personas con los animales del monte. Es además parte de un entramado de relaciones que incluye a los animales de cría, relevantes en el modo de vida ganadero y campestre que caracteriza a la zona. En tanto es frecuente la faena de corderos, vacas y gallinas para el consumo, así como el "control" de depredadores, el contacto con la muerte de animales y la transformación de su carne en alimento son cuestiones cotidianas vinculadas a la reproducción de la vida. Esto contrasta con una sensibilidad urbana horrorizada con la muerte de animales con los que no se tiene proximidad física, y cuyos lugares de muerte son confinados y separados del proceso de consumo (Descola, 1998; Süssekind, 2010). 
Las distintas percepciones sobre animales suelen confrontarse, particularmente cuando está implicada la muerte animal. En el contexto de una renovada sensibilidad hacia los animales (Carman, 2017) la caza está siendo cuestionada por organizaciones animalistas y conservacionistas, y también por una parte de la opinión pública identificada con dicha sensibilidad. En los últimos años asistimos a una reverberación del tema principalmente en las redes sociales.

La actividad productiva que predomina en la zona de Paso Centurión es la ganadería extensiva tradicional. Sin embargo, desde la primera década de este siglo tiene un fuerte empuje la forestación con especies exóticas (eucaliptus principalmente) (Gautreau, 2014) . Por otro lado, desde finales del siglo XX el área es señalada de interés para la conservación por su alta biodiversidad. Configurando un proceso de ambientalización (Ferrero, 2005), el área es incorporada dentro del sistema de conservación pública a escala departamental y luego nacional. Asimismo, múltiples intervenciones en conservación por parte de ONGs e instituciones de investigación comenzaron a llegar a la zona .

Los cambios en el uso del suelo a impulsos del agronegocio, las nuevas sensibilidades respecto a los derechos de los animales que se están generando a nivel global, y los procesos de ambientalización generados en la zona de Paso Centurión, entretejen una serie de complejas relaciones con las prácticas locales de caza de subsistencia. En este trabajo exploramos antropológicamente aspectos éticos, epistémicos y materiales implicados en los discursos y prácticas de caza en Centurión. Observamos desde el punto de vista de los pobladores locales las relaciones con una ética y discurso conservacionista de creciente impacto en el lugar, y desde el punto de vista de activistas de la conservación, cambios que ocurren por el contacto con la caza de subsistencia en este contexto particular.

Emprendimos una aproximación etnográfica utilizando principalmente la observación participante, múltiples conversaciones informales y entrevistas no estructuradas realizadas tanto a pobladores locales como a activistas conservacionistas . Exploramos discursos sobre caza en una localidad rural pequeña donde la ganadería tradicional, los monocultivos forestales y la conservación de biodiversidad reconfiguran territorios, prácticas y discursos sobre la naturaleza y los animales. Observamos estos cambios y perspectivas en tres ejes: las disímiles prácticas y nociones de equilibrio, sustentabilidad y gestión de los animales; las estrategias locales de legitimación frente a los discursos condenatorios hacia la caza, como la diferenciación entre cazadores locales y foráneos; la no propiedad de los animales como eje moral de la práctica en la localidad y los acuerdos en torno a la caza como medio de subsistencia. En forma transversal el estudio nos permitió comprender aspectos epistemológicos y ontológicos de las relaciones entre humanos y animales no humanos y las articulaciones entre distintas perspectivas en diálogo.

Consideramos que tanto las prácticas como el ethos y la ética que hallamos en relación con la caza de subsistencia en el lugar de estudio, así como sus cruces con políticas y prácticas conservacionistas y con cambios recientes en los usos del suelo, pueden ser análogos en muchas localidades del interior rural del país, aún inexploradas por las ciencias sociales.

\section{Un paso de frontera entre la ganadería, la forestación y la conservación}

Paso Centurión y Centurión son dos parajes contiguos que conforman una unidad social y territorial denominada comúnmente como Centurión. Esta localidad se encuentra al noreste del Uruguay, en el departamento de Cerro Largo. Está comprendido en la cuenca de la laguna Merín y limita con Brasil mediante el río Yaguarón (Figura 1). En tanto sitio de frontera, es un 
espacio culturalmente híbrido y lingüísticamente bilingüe y diglósico, donde se hablan una variedad del llamado Dialecto Portugués del Uruguay (DPU) y el español (Behares, 2007). Su paisaje serrano combina ganadería tradicional de bovinos y ovinos, montes, quebradas y múltiples cursos de agua, antiguas casas de terrón dispersas en predios pequeños, medianos y grandes, otras de materiales convencionales, en un núcleo de viviendas MEVIR . En distintos puntos, campos forestados con eucaliptus que crecen sin control ni podas recuerdan que un momento de gran empuje de esta producción fue interrumpido por medidas cautelares de la Junta Departamental, con el apoyo de la población local, argumentando la condición de Reserva

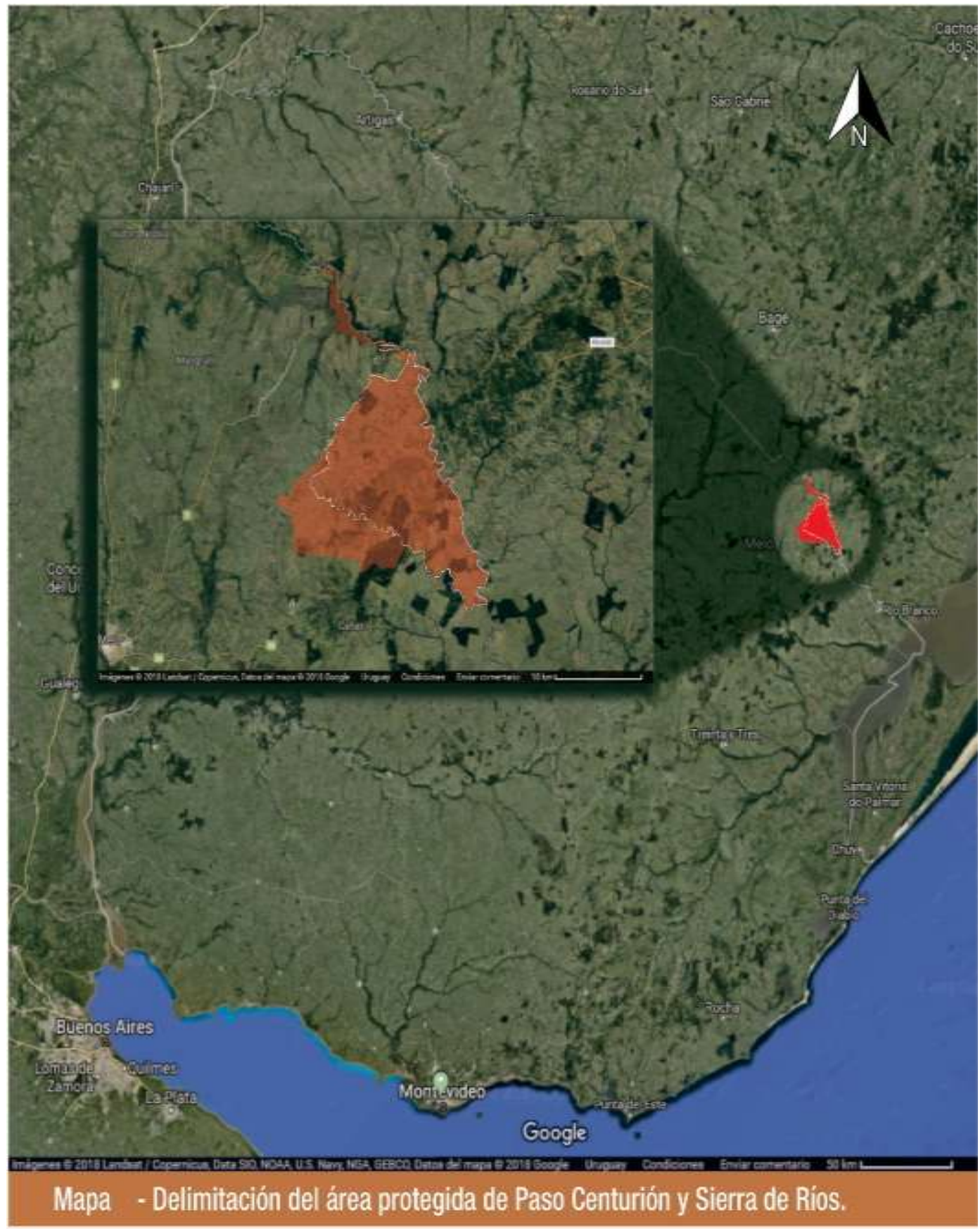
del área que regía desde 2007(Garay et. al. 2019).

Figura 1. Mapa del Área Protegida Paso Centurión $\mathrm{y}$ Sierra de Ríos y Suelo Rural Protegido delimitado por las Directrices de Ordenamiento Territorial. Fuente: Garay et al., 2019. localidad es un caserío rural de difícil acceso adonde recién en este siglo han llegado los servicios estatales de agua y luz a la zona más poblada. $\mathrm{Su}$ población residente es pequeña, tiende al

- krea propuesta para su ingreso al Sistema Nacional de Áreas Protegidas (2018) - (Área delim tada con perimetro Rojo)

- Suelos Rural Protegido de acuendo a las Directrices Departamentales de Ordenamiento Territorial de la Junta Departanental de Cerro Largo (2012) - (Area del mitada con perimetro Blanco\}) 
envejecimiento, la disminución, y presenta promedialmente índices socioeconómicos muy bajos, que lo han hecho objetivo de diversos planes sociales estatales (Garay et al., 2019).

Las actividades económicas y productivas se basan en la producción pecuaria de escasa tecnificación, la ganadería dedicada a la recría de bovinos y ovinos, realizada por productores de pequeños a grandes, y que emplea a parte de la población en forma permanente o en "changas" , oficios rurales tradicionales como el de alambrador, y trabajos zafrales como la esquila. Además de trabajar en las tareas productivas señaladas, las mujeres son generalmente las encargadas del trabajo reproductivo como el cuidado y crianza de los hijos, las tareas del hogar, el cuidado de las personas mayores, etc. La distribución de la tierra y la riqueza presentan grandes niveles de desigualdad.

A comienzos del siglo XXI la forestación industrial tiene un gran avance en el área. Desde la década del noventa la forestación con especies exóticas (Eucalyptus spp. y Pinus spp.) se expande en la región, mientras retrocede la actividad emblemática: la ganadería extensiva. Entre sus impactos se destaca que fomenta la concentración de tierras, el aumento de su precio y la reducción de los productores familiares, aunque se debate sobre la complejidad de factores de este proceso de retracción (Gautreau, 2014). En Centurión estos impactos son acusados por los pobladores que mencionan la migración de familias a raíz de las compras de tierras por parte de multinacionales silvícolas en las primeras décadas del siglo, acelerando un proceso de despoblamiento preexistente. Según los pobladores de Centurión el agronegocio forestal incrementó el desplazamiento de pequeños productores y asalariados, lo que coincide con datos estadísticos del censo agropecuario .

Los impactos ambientales de los monocultivos forestales son también objeto de debates - Algunos efectos sobre la biodiversidad son la pérdida y fragmentación de vastas extensiones pastizales naturales, el principal ecosistema del país; reducción de diversidad y abundancia a escala local en aves y mamíferos nativos (Brazeiro, Cravino, Fernández, \& Haretche, 2018); cambios en las dinámicas animales y vegetales y la proliferación de especies dañinas para los productores, como jabalí y cotorra (Gautreau, 2014). Los pobladores de Centurión también asocian esta expansión forestal con el desarrollo de plagas animales, acusadas de obstaculizar las producciones de menor escala.

Por otro lado, desde la década de 1990 el área de Paso Centurión y Sierra de Ríos es señalada de interés para la conservación, confrontado con el agronegocio silvícola en tanto usos de suelo no compatibles. El área es considerada muy relevante desde el punto de vista de la singularidad y el estado de conservación de ecosistemas, paisajes, especies de fauna y flora. En cuanto a la fauna, se destaca por encontrarse allí la mitad del grupo total de especies registradas para el país (SNAP, 2018). Están presentes casi la mitad de las especies de mamíferos reportadas a nivel nacional así como especies raras y nuevas para el Uruguay, como el Puma yagouaroundi o yaguarundí, y otras que se encuentran bajo alguna categoría de conservación, como el oso hormiguero chico (Tamandua tetradactyla), la paca (Cuniculus paca), el tatú de rabo molle (Cabassous tatouay), el coendú (Sphiggurus spinosus), la cuica de agua (Chironectes minimus) y el aguará guazú (Chrysocyon brachyurs) (Grattarola et al., 2016).

El área fue declarada Reserva Departamental en 2007 e ingresa al Sistema Nacional de Áreas Protegidas (SNAP) . Es categorizada como Suelo Rural Natural Protegido por las Directrices de Ordenamiento Territorial y Desarrollo Sostenible de Cerro Largo en 2016 (Garay et al., 2019). Asimismo, se vienen desarrollando investigaciones e intervenciones en conservación por parte de instituciones de investigación y organizaciones de la sociedad civil. Las dos organizaciones sociales actualmente más relevantes en el territorio, por su importancia material y simbólica en estos últimos años, son: la Asociación Civil Julana (Jugando en la 
Naturaleza) y la ONG COENDU (Conservación de Especies Nativas del Uruguay).

Julana está integrada mayormente por biólogos y se dedica a la educación ambiental crítica, mediante metodologías lúdicas y participativas, apunta al trabajo con las comunidades locales y al aprendizaje colaborativo, por lo que podemos llamar a su enfoque de etnoconservación (Süssekind, 2010). COENDU se centra en la conservación de la flora y fauna nativa fundamentalmente mediante acciones de sensibilización, educación, control de ilícitos, desarrollo del ecoturismo e institucionalización ambiental. Esta organización postula un conservacionismo al que llamaremos strictu censo (Süssekind, 2010) o radical. Su perspectiva y accionar ecocéntricos parten de que naturaleza y sociedad son mutuamente excluyentes, y de la existencia de un orden natural regido por leyes naturales cuyo "delicado y perfecto equilibrio se mantuvo hasta el momento en que el hombre entra con toda su ignorancia y presunción" (McConnell citado en Foladori, 2005: 87) .

Conformada a partir de redes sociales, esta ONG toma a Centurión como uno de sus lugares de trabajo y el ingreso del área al SNAP fue uno de sus principales objetivos. En los últimos años una pareja de miembros de COENDU adquirió un terreno y se instaló de forma permanente en la localidad. Además, uno de ellos asume como Inspector Medioambiental Municipal, un nuevo cargo dependiente de la Intendencia Departamental de Cerro Largo. En el frente de su casa colocaron un cartel donde se lee: "la caza de especies nativas está prohibida", el número de la ley citada y los logos de la ONG. Son tiempos de fuertes campañas de activistas en contra de la caza y que llegan a implicar a la propia Dirección de Medio Ambiente.

Este cartel es el único existente en el espacio público en la localidad, a excepción de otro ubicado a la entrada que fue colocado también por la ONG con colaboración de la Intendencia departamental. Esta forma de comunicar es, por tanto, singular, despersonalizada y coercitiva. Asimismo, el cartel es la marca espacial de un nuevo sujeto en el territorio, COENDU, al que legitima como representante de dicha legalidad. Esta organización también tiene un poder político-administrativo a partir del nombramiento del Inspector Medioambiental municipal. El cartel coloca una nueva mediación en las relaciones humanos-animales, cuyas implicancias no son apenas simbólicas sino también políticas y territoriales. El miembro de COENDU residente e Inspector medioambiental será mirado por los pobladores como "el que cuida a los animales", pero también de quien hay que cuidarse a la hora de cazar: Têm que se cuidar de ele, pero ta bravo, ta bravo pa cacería... (M. pobladora).

\section{Mulitas, carpinchos, pacas: buenos para comer o proteger}

En Centurión, la caza ha sido tradicionalmente una forma de sustento alimenticio, de eliminación de animales considerados peligrosos o dañinos, una actividad vinculada al esparcimiento y a las relaciones con el entorno ligada a las actividades de campo y a la vida cotidiana. Según las narrativas locales y las observaciones de campo, la mulita (Dasypus septemcinctus), el tatú (Dasypus novemcinctus) y el carpincho (Hydrochaeris hydrochaeris) son las especies cazadas más frecuentemente. La bibliografía antropológica da cuenta de que en las zonas rurales de la región es compartido el carácter histórico y cotidiano de la caza de carpincho (Pizarro et. al. 2016) y el "apetito pampeano" por su carne (Sordi, 2015).

Aunque su importancia como abastecimiento de carne da muestras de haberse reducido mucho, la carne de mulita y del tatú son generalmente apreciadas en Centurión: "ah son preciosos, se le pone ajo... tiene una grasita blanca tan rica.../ Asado... que queda bien asadito en el cuero, pegado en el casco... jeso queda precioso!" (B. pobladora). Estos animales se cazan con perros y también con trampas que se colocan en las entradas de sus madrigueras, y participan en su caza tanto varones como mujeres . La carne de carpincho también es valorada, 
y se destaca "la manta" asada, aunque bien puede prepararse en milanesas . Lo importante es sacarle bien la "catinga" o "morringa", que tiene mal gusto, que en términos anatómicos es una glándula sudorípara: "va en el modo de preparar, es depende cómo lo prepares. Pero... que es lindo es lindo" (I. pobladora).

En los informes técnicos sobre especies prioritarias para la conservación, a nivel nacional tatús, mulitas y carpinchos son citadas como las más frecuentes en la caza de subsistencia y comercial (SNAP, 2013). De acuerdo con la normativa vigente, todas estas especies son consideradas especies zoológicas nativas cuya caza está prohibida. Esta situación coloca en oposición una serie de prácticas muy arraigadas en los sistemas de uso y significado de la naturaleza locales y rurales con la normativa que regula la caza. Además, la caza de estas especies es impugnada por el conservacionismo stricto sensu.

Para COENDU la caza es un factor relevante en la disminución de poblaciones animales, y ante la pregunta acerca de la proporcionalidad con respecto a otros factores de impacto una respuesta usual es que "todo suma". Así fundamenta la concentración de parte de su activismo en combatir esta práctica, denunciar cazadores comerciales, hacer campañas mediáticas. En el ámbito académico, la caza es colocada como una amenaza para los mamíferos en Uruguay (MNHN, 2017). Pero si bien se admite que los factores de impacto sobre la fauna están pobremente evaluados, la literatura apunta que en el mundo la pérdida de hábitats es la principal presión para los mamíferos terrestres, en lo que este país no sería una excepción: "La pérdida, degradación y fragmentación de hábitats como resultado de la expansión e intensificación de las actividades ganaderas, agrícolas y forestales es la principal amenaza para el conjunto de los mamíferos continentales" (SNAP, 2013: 191).

Otra de las carnes de monte más preciadas en Centurión es la de la paca (Cuniculus paca). Es casi una regla que quienes la probaron la tengan en alta estima y digan que su carne "es como la del lechón". Generalmente se caza con trampa y con cebos como naranjas y boniatos, aunque también se cuenta que ella misma se acerca a las casas a comer en la época de las naranjas e incluso que la especie se extendió por donde había naranjos y plantación de boniatos. Los relatos señalan que la práctica hortícola era frecuente en generaciones pasadas, asociando la abundancia de gente, cultivos y pacas.

La paca escasea en los últimos tiempos, coinciden pobladores y diagnósticos biológicos, que la catalogan como especie frágil, amenazada y la hacen objeto de protección. Dentro del territorio uruguayo este animal solo ha sido citado en la cuenca del Yaguarón, lo que la torna más emblemática para conservacionistas que trabajan en el área. Para Beltrán y Vaccaro (2015) la idea de un determinado peligro ambiental legitima la intervención política; la gestión de las especies abre las puertas para la gobernabilidad del territorio. En la categorización de las especies como emblemáticas, paraguas, nobles, invasoras, plagas, etc. intervienen criterios no apenas restringidos a una coherencia ecológica sino también a valoraciones estéticas, políticas o a preferencias de manejo. La escasez de pacas, el sentido de su fragilidad dota a su caza de una gravedad especial, justifica el repudio y control sobre la caza de especies catalogadas como nativas, y normaliza la presencia conservacionista en el territorio.

La disponibilidad de pacas se redujo a un mínimo y por lo tanto también su caza. La causa adjudicada a esta disminución para los pobladores locales no es la cacería sino al contrario: al tratar sobre los stocks poblacionales de algunas especies desarrollan otras hipótesis. La caza de pacas se halla en declive por la ausencia de estas y no por considerarse una amenaza a su sustentabilidad. También la caza declina por la falta de personas, de cazadores: ¿quién va a cazar si no hay gente? argumentan. 


\section{Gestionar los animales: una cuestión de equilibrio}

La gestión de los animales por parte de pobladores locales obedece a criterios muy distintos de la gestión ambiental institucionalizada y de lo establecido en la normativa que regula la actividad cinegética. Para los cazadores locales, existen reglas para que la caza no afecte la disponibilidad futura de presas de caza, fundamentadas en conocimientos acerca de los animales. Las mulitas se cazan en una época determinada (no reproductiva), que corresponde a "los meses sin r" y los carpinchos sin restricciones en cuanto a su época de reproducción. Estos conocimientos y reglas aseguran que si ciertos animales escasean no se debe a que se los cace. Antes se cazaba mucho y había muchos carpinchos, por ejemplo, lo que no implica que la caza fue la causa de ese descenso.

Las distintas formas de gestión se rigen por principios que, en el sentido ecológico de la gestión cinegética pueden entenderse como de sustentabilidad de la especie (Kumpel et al., 2010; Kunz y Blum, 2009; Robinson y Redford, 1994), aunque en este caso están basadas en concepciones de sustentabilidad muy distintas. Como señala Ingold (2012) el concepto de gestión o manejo puede tener un sentido burocrático y uno cotidiano, que implican distintas formas de relacionarse y concebir el ambiente: respectivamente, un objeto a ser gerenciado mediante la planificación o algo que siempre ha variado, un campo de actividad donde suceden las operaciones de manejo. En tal sentido el autor distingue la gestión profesional orientada a organizar y administrar la naturaleza, del manejo por parte de las personas como parte de su vida cotidiana cuyo objetivo no es la gestión en sí misma. Estas personas se ocupan de las cosas "como vienen": "un proceso de ir andando a través del ambiente más que un proceso de ir realizando objetivos que han sido fijados con anticipación" (Ingold, 2012).

Estas formas de entender la sustentabilidad y la gestión de la sustentabilidad involucran diferentes maneras de relacionarse con el ambiente. En las relaciones entre conservacionistas y comunidades locales se ponen en juego estas distintas formas de concebir la sustentabilidad de la caza y las poblaciones animales, dando lugar a conflictos y fracasos en proyectos de gestión ambiental (Blaser, 2009; Ingold, 2012). En nuestro caso estas diferencias originan desentendimientos e imputaciones de irracionalidad en ambos sentidos entre estos sujetos, así como sentimientos de persecución por parte de los pobladores, que en consecuencia desarrollan estrategias discursivas de legitimación de sus prácticas.

Desde nuestra perspectiva, la caza está integrada en la vida y la moralidad de la población de Centurión y constituye una forma específica de relación con los animales silvestres, con sus clasificaciones, conocimientos y también controversias entre las personas .

Por otro lado, al indagar si la categoría de especies amenazadas tiene sentido en el sistema local de usos-significados de la naturaleza y los animales, se pone de manifiesto una distribución de lo amenazado y lo abundante radicalmente distinta a la de la conservación académica y activista. En lugar de la retórica de la amenaza de la ontología ecologista, en la visión local encontramos la abundancia. La abundancia de algunos animales que se percibe es relacionada tanto a la falta de gente como a los actuales controles sobre la caza: una suerte de control sobre el control, de enajenación política de la gestión local de la naturaleza, que conlleva desequilibrio. En la ecología local la prohibición de matar hace que se reproduzcan sin control animales que provocan problemas en la producción agropecuaria, como comenta esta pobladora sobre los zorros:

"Ahora hay mucho más. Insectos también hay mucho más... Produce mucho y no dejan matar nada. Todo bicho que usté no mata produce ¿no?" (M., pobladora).

De esta cita se desprende que la caza opera como un medio de control de animales y así como una forma de mantenimiento del equilibrio. Al contrario de la percepción 
conservacionista, la caza es necesaria para la convivencia humanos-animales; para la biodiversidad, entendida como inclusiva de la producción. Si volvemos la mirada a la ecología científica, vemos que lo que esta entiende como desborde, exceso, también es controlado, mediante categorizaciones como plagas, especies invasoras y planes de gestión acordes (Beltrán y Vaccaro, 2015). Para la posición conservacionista stricto sensu de COENDU y corrientes como el animalismo, en cambio, la naturaleza sin intervención humana se autorregula hacia el equilibrio, por lo que rechaza el control de poblaciones animales que impliquen su muerte.

Cada una de estas formaciones onto-epistémicas tiene su propia noción de equilibrio de acuerdo con ideales de cómo debería estar compuesto el mundo, cómo debería ser la naturaleza, a la que conoce y gestiona mediante sus propios métodos. Los stocks de animales y el impacto en ellos de la caza u otras actividades humanas no son independientes de los mundos en cuestión. Desde una perspectiva ontológica:

Há uma realidade independente que está sendo vista por diferentes observadores, conforme suas respectivas visões de mundo? A resposta provisória que estamos dando a essa pergunta é não. Há sim diferentes realidades em competição, junto com ontologias que nesse caso são antagônicas (Almeida, 2013: 21).

A pesar de que la caza de subsistencia es importante histórica y culturalmente en la localidad, en las conversaciones se reitera que ha disminuido mucho. De acuerdo con las observaciones etnográficas, en los últimos años la importancia de la caza de carne de monte en la dieta de la población ocupa un rol marginal. Sólo en algunos hogares la caza y la pesca son medios principales o importantes de abastecimiento de carne. Estos casos respetan las normas éticas que ordenan la práctica: cazar para comer y que el cazador o cazadora sea local. La caza de una mulita no contradice ni el sentido común ni el equilibrio (concebido a la vez como ambiental y social), sino que lo refuerza. No es menor que sea un funcionario policial, quien además es productor y poblador local, el que ponga en palabras esta lógica

Tenemos que tener un poco de criterio y sentido común, es decir, si un lugareño se caza una mulita para comer con la familia, bueno, ta dentro de lo normal. No se debe, pero está dentro del equilibrio ese... No es lo mismo que venga uno de afuera y se lleve diez mulitas, por decir un ejemplo ¿no? A ese sí tenemos que aplicarle la normativa o la ley. Si un lugareño caza una mulita para comer con su familia, una al mes, no le va a afectar, no va a afectar tanto el ecosistema y lo tenemos de nuestro lado porque si ese lugareño que le gusta cazar o que tiene la tradición familiar, porque es así, de comer cada tanto una mulita o un tatú o un carpincho, no va a dejar que venga alguien de afuera a cazarle porque él no va a poder cazar después. Entonces bueno, nos ayuda a nosotros a tener el control. Lo tenemos de nuestro lado. (R. Funcionario policial y poblador).

Al contrario de la política racional y de la perspectiva conservacionista stricto sensu, de acuerdo con este fragmento de entrevista la sustentabilidad de los animales mencionados depende de que puedan ser cazados, cada tanto, para "comer en familia", manteniendo el equilibrio del lugar. Si esto no es alterado, entonces las mismas personas que cazan y/o comen presas de caza serían aliadas de "la conservación" para evitar la incursión de cazadores foráneos, con prácticas depredatorias. Así, esta noción de equilibrio que traducimos como sustentabilidad depende de poder cazar a algunos animales y de la comensalidad. De esta manera, el uso de la ley en forma relativa y la caza reglada de estos animales actualiza la onto- 
epistemología, identidad y política cultural de la naturaleza arraigada en el lugar (Escobar, 2000).

\section{Cazadores de adentro, cazadores de afuera y chanchos jabalíes}

En torno a la caza del jabalí las cosas son muy distintas: para los pobladores este animal tiene connotaciones negativas como plaga asociada a la forestación. Junto a los zorros que "siempre existieron" pero que con la forestación se tornan plaga y "salen a depredar", los jabalíes aparecen en los relatos ya bajo la categoría de plaga. Para la gente del lugar, además de amenazar la producción de ovinos y cultivos, estas plagas animales representan el abandono humano del territorio. En sus narrativas los monocultivos expulsaron a familias vecinas, bloquearon la visión de lejanía, de las casas vecinas y cercan el paisaje serrano con una selva oscura de árboles altos. La forestación significa una amenaza a la continuidad del lugar como se lo conoce y habita. En este contexto, el jabalí simboliza un modelo de territorio deshumanizado y de una naturaleza habitada por plagas únicamente .

La práctica de correr chanchos es más frecuente en la cercana localidad de Sierra de Ríos, caracterizada por una mayor extensión de explotaciones forestales que Centurión. En una visita a una familia que trabaja en una estancia de dicha zona, rodeada de florestación , conocimos una jauría destinada a este fin. Allí la caza de jabalíes, a caballo y con perros, satisface una función recreativa: "yo no pago para ir a un baile, a mí me encanta salir a cazar y las carreras" [de caballos] me explica I. A la vez cubre una necesidad alimenticia: "carne pa la olla", dice su esposa Iv. pobladora, "con el precio de la carne [de cordero o vaca]. Además, más sano, porque no tiene remedios ni nada".

Incluso aunque la caza trofeo parece muy distante de allí, algunos cráneos de jabalíes cuelgan para secar sus tejidos en las rejas de una ventana del casco de la estancia, enorme y deteriorado. El capataz del campo y cazador es a veces llamado por propietarios de otros predios para que vaya a cazar jabalíes que están haciendo algún daño, y aquel suele llamar a su hermana para que le acompañe.

En Centurión el jabalí es reciente, escaso, es un foráneo apenas incorporado a la vida social, pero se lo percibe abundante en las inmediaciones.

Carpincho, tatú y la mulita bueno... el que lo agarre lo va a comer, eso sabelo que lo va a comer. Ta el jabalí, pero el jabalí es plaga, el jabalí no le... hay manojos pero ta... también es algo que lo usan como carne. I. (pobladora),

Aunque se mencionan eventuales experiencias de caza de jabalí, dice T. (poblador), "acá no hay mucho chancho", y la caza en la zona se enfoca en mulitas, tatús, carpinchos, liebres. El jabalí es más comúnmente asociado a cazadores de la ciudad de Melo (capital departamental y ciudad uruguaya más próxima a Paso Centurión), que se mueven en su búsqueda por la zona sobre todo en semana de turismo.

En tanto el jabalí es considerado una plaga favorecida por la forestación, agroproducción ampliamente rechazada por los lugareños. Desde sus perspectivas, ese paisaje ajeno, fabril de los bosques artificiales, es albergue seguro para fieras poco conocidas, a su vez atractivas para cazadores de otros lugares y con otras formas de cazar. En efecto, la caza del jabalí requiere una tecnología y organización cinegética específica: generalmente se trata de ir tras su rastro en la noche, a pie o a caballo, con varios perros enseñados y que cumplen distintos roles, un cuchillo largo o arma de fuego para ultimar a la presa una vez que los perros la tienen inmovilizada. Muy distinto a las prácticas de caza de carpinchos y tatús, la cual implica dispositivos tecnológicos más simples. Al estar asociado este animal a la forestación con especies exóticas, jabalíes, eucaliptus y cazadores foráneos conforman un conjunto de signo negativo, un clan exógeno, la 
alteridad .

Así el significado local de este animal está atravesado por la división entre caza local y foránea, que a nuestro entender es crecientemente remarcada para legitimar la caza local, como consecuencia de la propia incidencia del conservacionismo cuestionador y controlador de la caza. La frontera adentro/afuera parece reforzarse proporcionalmente a los sentimientos de persecución y control hacia la caza practicada por los lugareños. En una entrevista, E. (pobladora) diferencia entre caza local y la practicada por los de afuera, presentándola en términos de un desigual derecho a la caza:

E.: Si vienen camionetas (...) de gente de Melo a cazar y cazan, ¿y los que están aquí no tienen derecho a cazar? Los de afuera vienen y cazan...

M.: ¿Y por qué decís que los de afuera sí pueden cazar y los de acá no?

E.: Claro eso yo no sé... porque aquí comentan eso ¿no? Dicen "Ah dice, esa gente si agarran a las personas con la caza lo llevan preso o pierde arma, pierde todo... ¿Y cómo vienen de Melo, varios ¿no? y cazan?

La caza por no lugareños es puesta en tela de juicio tanto por conservacionistas como por la población local. Esta última subraya la sustentabilidad y legitimidad de la caza de subsistencia practicada por habitantes locales contrastándola con la que realizan personas foráneas como deporte o comercio, a la que acusan de depredar y hacer de la caza un negocio. Planteamos la hipótesis de que, ante las presiones sobre la caza, se tiende a remarcar la diferencia entre "los de adentro y los de afuera". Como en otro caso documentado en la región, una zona ambientalizada en el Delta del Paraná, Argentina, más que por una razón instrumental, como las motivaciones como comer, vender, deporte- los lugareños distinguen los cazadores por su lugar de origen desde "una razón abiertamente cargada de valores" (Pizarro, Maestriperi, y Liftenegger. 2016: 66). El significado de la caza, de los animales y de la naturaleza difiere entre cazadores locales del medio rural, para quienes la caza ha proporcionado alimento en tiempos de carestía, y los de la ciudad, cuyas motivaciones son otras (Sánchez Garrido, 2009).

Es interesante señalar que el rechazo al jabalí se encuentra en la biología de la conservación por razones ecológicas, ya que es considerado una especie invasora. En cambio, en el conservacionismo representado por la ONG COENDU, si bien se promueve la protección de lo "nativo", no se rechaza ni se promueve el control de animales "exóticos" o "invasores" mediante la caza ni otras formas de muerte. Esto configura una controversia entre conservación científica y este conservacionismo activista con respecto a la gestión ambiental y la caza. Además, una de las razones principales del rechazo de esta ONG a la caza del jabalí radica en la modalidad predominante dentro de esta actividad cinegética. La caza del jabalí suele llevarse a cabo con perros que, durante la búsqueda de los jabalíes en los montes, en ocasiones atacan a la fauna nativa.

En el variado espectro de organizaciones con temáticas ambientales que trabajan en el lugar de estudio, la postura sobre la caza difiere sustancialmente, y aún a la interna de COENDU existen importantes matices en cuanto a problemáticas específicas, entre ellas la caza. Algunos miembros rechazan la caza por considerarla una práctica superada en términos evolutivos, otros la toleran cuando se trata de un medio de subsistencia "imprescindible" de familias del campo. Estos últimos admiten la caza en determinados contextos en Centurión y rechazan la incursión de cazadores foráneos, por lo que, a pesar de varias diferencias, existe un creciente consenso entre miembros de la ONG y lugareños acerca de una clasificación de cazadores según su lugar de origen. 
Si bien desde distintas ontologías de la naturaleza, estas perspectivas han permitido articular acciones comunes entre funcionarios policiales, pobladores y conservacionistas, como el control de cazadores foráneos en semana de turismo, siendo su correlato la flexibilidad del control hacia la caza local. Esto puede verse como un puente pragmático entre ontologías (Almeida, 2013: 21-22), que atenúa las presiones y controles sobre la práctica: "Nos conflitos ontológicos há coalizões e há alianças possíveis". Puente que, al permitir la práctica de la caza por familias pobladoras, posibilita también la diferencia, la multiplicación ontológica ante el avance de una ontología universal (Almeida, 2013). La multiplicidad de relaciones y conocimientos sobre la naturaleza y los animales se relaciona con la pluralidad de mundos ante el avance del mundo único (Escobar, 2016). En tal sentido, en los territorios ambientalizados como el que estudiamos, no están en juego apenas cuestiones de sustentabilidad de la naturaleza sino de conocimientos y mundos posibles. Las alianzas entre pobladores y ONG pueden ser claves para la defensa del territorio, en términos de biodiversidad y pluriversidad.

\section{Antes cazar pa comer y no robar... Caza, propiedad de los animales y subsistencia}

Visitamos algunas veces a J., un poblador de Centurión con quien algunas pobladoras recomendaron hablar en virtud de que es cazador y sabe todo de bichos. En una ocasión, la entrevista coincidía y se aromaba con la cocción de una mulita al fogón (horno a leña), muy adobada, y cuando estuvo pronta fue el momento de culminar la conversación. En otra ocasión hablamos largamente con J. y con R. -vecino que se encontraba en su casa- acerca de animales y varias experiencias de encuentros con estos en los montes y campos, tema en que inevitablemente se mezclaba la caza. J. y R. explican la legitimidad de la caza de animales silvestres en función de que estos no son de nadie: a diferencia del ganado, se mueven por los campos, montes y arroyos, no están circunscriptos a un territorio ni pertenecen a un dueño, no los detienen los alambres.

Cazar animales "que no son de nadie" es una práctica moralmente aprobada en el lugar. Según R.

los carpinchos, por ejemplo, no son de nadie, hoy están ahí y mañana ya no, están andando. En cambio, las ovejas son propiedad. Da un ejemplo: si yo tuviera una tierra no me molestaría dejarlo a él que vaya a cazar un carpincho; el carpincho no es mío" (Diario de campo, 2017).

La contrastación entre caza y abigeato es muy frecuente en las narrativas de Centurión, evidenciando una ética determinada: cazar para comer es una actividad lícita en tanto no viola la propiedad de los animales y no es condenable, mientras que el robo de ganado es inadmisible. Esta lógica no pone el foco en las especies sino en una relación de propiedad. Es decir, lo que las torna pasibles de ser cazadas es que estas no tienen dueño, mientras que otros criterios, claves para el conservacionismo y la normativa de fauna -como la distinción nativo/exótico- o la valoración de la biodiversidad per se, no forman parte de la ontología del lugar.

No obstante, si bien la normativa nacional vigente prohíbe la caza de especies nativas (salvo excepciones que los organismos competentes establezcan), la considera una falta , mientras que el robo de ganado en tanto delito se castiga con prisión. Esto motiva las críticas de conservacionistas, para quienes la caza debería también constituir un delito y castigarse como tal.

Animales de caza y animales domésticos productivos se diferencian claramente en 
términos de propiedad y en las formas de apropiarse: estos últimos no se cazan, se carnean, se faenan. La posibilidad de que la ley de fauna se cumpla en el lugar trastoca estos límites que ordenan las relaciones con los animales y la economía de caza: "Siempre fui pobre y voy a morir pobre. Siempre cacé para comer. El día que no me dejen cazar más voy a tener que cazar ovejas" (J. poblador). Si cazar especies nativas se convierte en un problema, el oxímoron "cazar ovejas" advierte que, desde la perspectiva local, proteger a los animales de caza es incluirlos en la esfera de la propiedad, lo que trastoca la ecología política del lugar. Cruzar el límite de la propiedad como criterio organizador de las formas de apropiación de la fauna acarrea desorden social.

Cazar animales sin dueño, respetar reglas transmitidas intergeneracionalmente (como la veda de mulitas en época reproductiva), cazar para comer, ser lugareño... son parte del marco social y ético que regula la caza en la localidad, que asegura su sustentabilidad y legitimidad.

Ah se cazaba sí. Mis hijos nomás pasaban cazando, pescando. Cazando y pescando. Sólo pa comer. Cazaban carpincho, cazaban tatú, pescaban. Yo me crié en el Rincón, todos eles se criaron nel Rincón... en la pobreza ¿no? Si no cazaban bichos pa comé... tudus se criaron na pobreza. Cazaban, saían cazar... (...) carne pa comé... antes cazar que robar noé... a palabra: [subraya] antes cazar pa comer y no robar... (M. pobladora).

A. sólo come la carne de carpinchos que caza y de peces que pesca. Este poblador del monte carece de tierra y animales, hace changas como peón o constructor. Dicen sus vecinos y familiares que no vende jamás carne de caza, por más que le pidan, pero sí intercambia con vecinos por otros alimentos o por espacio en la heladera para la carne. Este cazador es citado a menudo por sus vecinos y familiares en las conversaciones sobre caza, en las que sirve de ejemplo para situar las cosas en su lugar ante interlocutores siempre sospechosos de cuestionar la legitimidad de la caza: "Porque eu sei que aquí há una persona que caza, pero pa comer, carpincho" (E., pobladora). La caza de carpinchos es así amparada en una razón material, vital, presentada en oposición a la caza como medio de acumulación o por deporte.

Surge la pregunta de si esta justificación exclusivamente material y su desvinculación de otros aspectos -simbólicos, afectivos, recreativos- de la caza es tan reciente como los propios discursos condenatorios hacia la práctica. En otras palabras, si cuando cazar no estaba en tela de juicio era preciso subrayar su relación con la subsistencia, diseccionar las motivaciones en torno a una práctica social compleja y multidimensional. Nuestras aproximaciones etnográficas no nos permiten responder a esta pregunta, pero sí sospechar que, más que una práctica para cubrir necesidades materiales, la caza es parte de un modo de vida en transformación; una forma de relacionamiento con los animales a la vez material y simbólico, una práctica de conocimiento, de esparcimiento, una relación cercana con los animales. Actualmente ese componente material es el que resguarda esta práctica de la condena que fomenta la ética conservacionista stricto sensu. La presión de discursos y controles conservacionistas empuja a demarcar el aspecto económico, donde la condena ambientalista encuentra un límite humanista, antropocéntrico.

A veces dentro del conservacionismo radical la caza se tolera cuando es indispensable para satisfacer necesidades alimentarias, aunque pocas veces se hace referencia a lo que esta implica en tanto práctica cultural, a su dimensión onto-epistémica. El contacto directo con las personas y sus realidades cotidianas hace que en ocasiones las posturas anticaza se relativicen, en particular al tratarse de caza de subsistencia practicada por familias de escasos recursos económicos. Así, M. de COENDU -que se autodefine ante nosotros como un "anticaza total"presenta en una entrevista la contradicción experimentada cuando una campaña de la ONG de 
recolección de firmas para pedir el ingreso de Centurión al SNAP lo llevó a algunos hogares:

Conocí una sencillez fuerte pero linda y ahí entendí... (...) ahí entendí... una familia que eran dos veteranos que tenían una huerta y ovejas, y ahí no sé cómo salió el tema, ellos me dijeron.... Claro, de qué viven, (...) ¿de qué vive esta gente? (...) Viven de la huerta... comen de la huerta, tienen una vaca que les da leche... cada tanto un cordero, cada tanto matan una mulita o un animal también para comer (...). Y ahí primero tuve una... algo que me llegó mucho que es la caza como alimento posta, o sea, no es una familia que pase hambre, pero bueno, donde seguramente matar esa fauna nativa le hace la diferencia al mes.

Lo que se juzgaba como daño ambiental desde una perspectiva biocéntrica, pasa a ser visto en términos de respuestas a necesidades básicas, subrayándose el aspecto material de la caza como fuente de alimento. Esta postura coloca a la caza en términos de seguridad alimentaria y es más empática hacia las personas económicamente vulnerables que recurren a su práctica. Los discursos conservacionistas se reconfiguran en relación con una alteridad que se juzgaba moralmente como insensible e incluso inhumana desde el ideario de civilización y barbarie (Carman, 2017). Esto configura otro puente pragmático entre onto-epistemologías diferentes, que permite la alianza en lugar de la oposición. Si bien desde el conservacionismo se tolera la caza en función de una razón instrumental, desconociendo el significado que tiene en el mundo del otro, la articulación hace posible la existencia de la práctica y así también de dicho mundo.

\section{Conclusiones}

En Centurión, la caza es tradicionalmente un medio de sustento alimenticio; de eliminación de animales problemáticos; de esparcimiento y sociabilidad; ligada a las actividades de campo, a la forma de vida, epistemología y ontología del lugar. Mulitas, tatús, carpinchos, liebres, pacas, se cazan según reglas que aseguran su reproducción o que no la amenazan, reglas que se orientan según conocimientos ecológicos locales. La caza y la comensalidad en torno a estos animales actualizan la epistemología, identidad y política cultural de la naturaleza en el lugar.

El jabalí se considera plaga asociada a la forestación, agroproducción silvícola rechazada por sus impactos sociales, productivos y ambientales en el territorio. Si bien son muy comunes en otras zonas cercanas como Sierra de Ríos, en Centurión los jabalíes no abundan, por lo que la caza y consumo de su carne es muy eventual y remite a la asignada condición de especie invasora y foránea.

La caza es también, desde el punto de vista de los pobladores, una forma de control de animales que producen mucho. Así, es importante para el equilibrio, según su perspectiva ecológica y su modo de gestionar los animales. En esto no se diferencia de la ecología científica cuando esta última categoriza especies como plagas, exóticas, invasoras, y las gestiona en consecuencia (Beltrán y Vaccaro, 2015).

En cambio las prácticas que implican la muerte de animales es confrontada por la perspectiva conservacionista stricto sensu que caracteriza a algunas ONGs.

En el proceso de ambientalización de Centurión son importantes las intervenciones en biodiversidad, entre ellas la COENDU, que representa la perspectiva mencionada. Existen desacuerdos y alianzas entre esta organización y los pobladores locales en el tema de la caza. Como desacuerdo mencionamos la consideración de esta como presión fundamental sobre la fauna, algo discutido tanto dentro del espectro ambientalista (incluyendo la esfera académica) 
como por la perspectiva local. En esta última los stocks animales y sus variaciones obedecen a distintas causas. Para los pobladores la abundancia de algunos animales se contrapone a la disminución de gente. El mal que aqueja a los lugareños es el despoblamiento rural, mientras que para el conservacionismo stricto sensu es prioridad la protección de animales emblemáticos.

En cuanto a las alianzas entre ONG y población local, la clasificación entre cazadores foráneos y lugareños y su distintiva valoración, es compartida y permite articular acciones de control de caza furtiva o depredadora, a la vez que legitima la práctica a nivel local. Asimismo, la caza en tanto medio de subsistencia, es crecientemente aceptada por activistas en contacto con situaciones de precariedad económica. En consecuencia, se tiende a demarcar el aspecto material de la caza, en detrimento de otros ligados a la epistemología y ontología del lugar.

Existen límites morales generados en la vida social y la experiencia cotidiana construida históricamente en la relación con el ambiente, en donde la caza de animales que "no son de nadie" es legítima. El criterio local coloca la propiedad privada como límite, mientras que la normativa nacional y el ideario conservacionista se rigen fundamentalmente por la clasificación nativo/exótico. Algunas versiones conservacionistas impugnan las clasificaciones que ordenan la moralidad compartida en Centurión, reconfigurando las relaciones entre humanos y animales no humanos en términos epistémicos, ontológicos y políticos.

En los territorios ambientalizados como el que estudiamos, no están en juego apenas cuestiones de sustentabilidad y gestión de la naturaleza sino también de conocimientos y mundos posibles. Ante el avance del agronegocio las alianzas entre pobladores y ONGs pueden ser claves para la defensa del territorio, la biodiversidad y el pluriverso. Pero también estas alianzas implican alternativas a una concepción dualista de la vida y una versión única del mundo, la naturaleza y la conservación. En Centurión, sus articulaciones en términos de conocimientos y prácticas son importantes para mantener o mejorar las relaciones humanoambientales, entretejidas con el bosque y la vida en el lugar.

\section{Referencias}

Almeida Mauro W. Barbosa de. (2013) Caipora e outros conflitos ontológicos. R@U | Revista de Antropologia da UFSCar, v.5, n.1, jan.-jun., p.7-28, 2013.

Behares, L. (2007). Portugués del Uruguay y educación fronteriza. In Portugués del Uruguay y educación bilingüe. (Brovetto, C., Brian, N. y Geymonat, J. ed., pp. 99-172). Montevideo: Administración Nacional de Educación Pública.

Beltran, O., \& Vaccaro, I. (2015). Animais selvagens convertidos em sujeitos políticos: a gestão pública da fauna nos Pirineus. Revista de Antropologia da UFSCar, 7(1), 37-58.

Binford, L. (1980). Willow smoke and dogs tails: hunter-gatherer settlement systems and archaeological site formation. American Antiquity, 45(1), 4-20.

Blaser, M. (2009). La ontología política de un programa de caza sustentable. American Anthropologist, 111(1), 81-107. 
Bozon, M. (1982). Chasse, territoire, groupements de chasseurs. Études rurales, 87(88), 335 342.

Brazeiro, A., Cravino, A., Fernández, P., \& Haretche, F. (2018). Forestación en pastizales de Uruguay: Efectos sobre la diversidad de aves y mamíferos a escala de rodal y del paisaje. Ecosistemas. Revista científica de ecología y medio ambiente, 27(3), 48-59.

Carman, M. (2017). El activismo proteccionista, o las disímiles imputaciones de dignidad a animales y humanos. Etnografías contemporáneas, 3(4), 128-155.

Carpinetti, B., \& Fa, J. E. (2012). El consumo de “Carne de Monte” en la Isla de Bioko: Una mirada desde la antropología ecológica / Wild meat" consumption in the Bioko Island: An outlook from ecological anthropology. Avá(20), 00.

Chamboredon, J.-C. (1982). La diffusion de la chasse et la transformation des usages sociaux de l'espace rural. Études rurales, 87(88), 233-260.

Dabezies, J. M. y Taks, J. (2017). ¿De quién son los animales que no son de nadie? Primeros cruces entre caza y conservación de la naturaleza. Trama, 8(8), 81-89.

De la Montaña Andrés, E. (2013). Cacería de subsistencia de distintos grupos indígenas de la Amazonía ecuatoriana (Vol. 22).

DeMello, M. (2012). Animals and Society. An Introduction to Human-Animal Studies. New York: Columbia University Press.

Descola, P. (1998). Estructura ou sentimento a relaçao com o animal na Amazônia MANA, 4(1), 23-45.

Escobar, A. (2000). El lugar de la naturaleza y la naturaleza del lugar: ¿globalización o postdesarrollo? In C. L. d. C. S. CLACSO (Ed.), La colonialidad del saber: eurocentrismo y ciencias sociales. Perspectivas latinoamericanas (pp. 68-87). Buenos Aires.

Escobar, A. (2016). Autonomía y Diseño. La realización de lo comunal. . Popayan: Universidad del Cauca.

Fabre-Vassas, C. (1982). Le partage du ferum: Un rite de chasse au sanglier. Études rurales, 87(88), 377-400.

Fernandes-Ferreira, H. (2014). A caça no Brasil: panorama histórico e atual. (Phd), Universidade Federal da Paraíba, Paraíba, Brasil. 
Ferrero, B. G. (2005). El surgimiento de una cosmografía ambientalista en el norte argentino. Société suisse des Américanistes / Schweizerische Amerikanisten-Gesellschaft, 69, 59-66.

Foladori, G. (2005). Una tipología del pensamiento ambientalista. In G. Foladori \& N. Pierri (Eds.), ¿Sustentabilidad? Desacuerdos sobre el desarrollo sustentable (pp. 83-136). México DF: Miguel Ángel Porrua.

Garay, A.; Santos C., Grattarola, F., Perazza, G.,Taks J,. Bergós, L., Gaucher L., y Chouhy, M. (2019). Informe final: Participación social, conocimiento experto y conflictos ambientales sobre uso del suelo, energía y biodiversidad en Paso Centurión (Cerro Largo, Uruguay). Udelar, CSIC, Programa I+D, Montevideo.

Gautreau, P. (2014). Forestación, territorio y ambiente 25 años de silvicultura transnacional en Uruguay, Brasil y Argentina (Trilce Ed.). Montevideo.

Grattarola, F., Hernández, D., Duarte, A., Gaucher, L., Perazza, G., González, S., Bergós, L., Chouhy, M., Garay, A., Carabio, M. y Rodríguez-Tricot, L (2016). Primer registro de Yaguarundí (Puma yagouaroundí) (Mammali: Carnivora: Felidae) en Uruguay. Boletín de la Sociedad Zoológica del Uruguay, 25(1), 85-91.

Cordeiro Rosas, G. K., U. y Drumond, P. M. (2007). Caracterização da caça de subsistência em dois seringais localizados no Estado do Acre (Amazônia, Brasil). Embrapa Acre. Documentos. Harris, M. (1968). The Rise of Anthropological Theory: a history of theories of culture. Londres: Routledge \& Kegan Paul.

Ingold, T. (2012). Ambientes para la vida. Conversaciones sobre humanidad, conocimiento y antropología. Montevideo: Trilce.

Kumpel, N. F., Milner-Gulland, E. J., Cowlishaw, G., \& Rowcliffe, J. M. (2010). Assessing sustainability at multiple scales in a rotational bushmeat hunting system. Conserv Biol, 24(3), 861-871. doi:10.1111/j.1523-1739.2010.01505.x

Kunz, J., \& Blum, C. (2009). Challenges in Estimating Sustainable Wildlife Harvest Rates. Retrieved from Göttingen, Germany: http://www.uni-goettingen.de/en/115492.html

Lee, B., \& Devore, I. (Eds.). (1968). Man the hunter. Chicago: Aldine.

Lowassa, A., Tadie, D., \& Fischer, A. (2012). On the role of women in bushmeat hunting - Insights from Tanzania and Ethiopia. Journal of Rural Studies, 28(4), 622-630. doi:http://dx.doi.org/10.1016/j.jrurstud.2012.06.002Marvin, G. (2003). A Passionate Pursuit: 
Foxhunting as Performance. The Sociological Review, 51(2_suppl), 46-60. doi:10.1111/j.1467954X.2004.00450.x

Marvin, G. (2006). Wild Killing: Contesting the Animal in Hunting. In T. A. S. Group (Ed.), Killing Animals (pp. 10-29). Illinois: University of Illinois Press.

Marvin, G., \& McHugh, S. (Eds.). (2014). Routledge Handbook of Human-Animal Studies. Abingdon, Oxon: Routledge.

MNHN (2017). La caza en Uruguay. Situación actual y perspectivas Posición institucional del Museo Nacional de Historia Natural. Montevideo.

Medrano, C. (2012). Cazando a la cazadora: cuestiones sobre la posición de la mujer toba en los ámbitos políticos y públicos, domésticos y privados. Bulletin de l'Institut Français d'Études Andines 41(1):123-146.

Montero Cruzada, S. (2017). Nosotros también somos indígenas: la vulnerabilidad del naturalismo en contextos occidentales de convivencia entre especies/We are also indigenous: the vulnerability of naturalism in western contexts of interspecies coexistence. Etnográfica, 21(1), 49-71.

Montero Cruzada, S. (2019). Encuentros de vida y muerte. Antropología transespecie y mundos ampliados entre cazadores y animales en el suroeste extremeño. (Phd), Universidad Pablo de Olavide, Sevilla.

On Ahn, M. M. (2018). Análise Antropogeomorfológica em Geossítio da história da mineração: estudo nas Minas do Camaquã - RS. Dissertação (Mestrado em Geografia). Universidade Federal de Pelotas, Pelotas.

Pelosse, V., \& Vourc'h, A. (1982). Chasse au sanglier en Cévennes. Études rurales, 87(88), 295307.

Pizarro, C., Maestriperi, E., \& Liftenegger, A. (2016). “¿Pero vos nunca comiste carpincho?” Resignificaciones locales de las prescripciones sobre el uso de la fauna nativa en los humedales del delta inferior del Paraná. AMBIENS, 2(3), 52-72.

Ritvo, H. (2007). On the Animal Turn. Daedalus, 136(4), 118-122.

Robinson, J., \& Redford, K. (1994). Measuring the sustainability of hunting in tropical forests. Oryx, 28(4), 249-256.

Sánchez Garrido, R. (2009). La caza desde la antropología social y cultural: Una aproximación al estado de la cuestión. Revista de Antropología Experimental, 9(14), 191-215. 
SNAP (2013). Especies prioritarias para la conservación en Uruguay. Vertebrados, moluscos continentales y plantas vasculares. Montevideo: MVOTMA, SNAP, MEC.

SNAP (2018). Proceso de ingreso de Paso Centurión y Sierra de Ríos al Sistema Nacional de Áreas Protegidas. Inédito.

Sordi, C. (2015). Guerra ao javali: invasão biológica, feralização e domesticação nos campos sulinos. Revista de Antropologia da UFSCar 7(1):59-77.

Süssekind, F. (2010). O rastro da onça. Etnografia de um projeto de conservação em fazendas de gado do Pantanal Sul. Museu Nacional- UFRJ, Rio de Janeiro. 